\title{
1. Bracing for change: making universities and firms partners for innovation in sub-Saharan Africa ${ }^{1}$
}

\author{
Glenda Kruss, John O. Adeoti, and \\ Dani Nabudere
}

Universities are traditionally known as centres of research and higher education. Globally, universities have undergone re-invention and renewal in tandem with societal change. In recent years, community development, and in particular the stimulation and spin-off of knowledge-intensive industries, has been proposed as a major contribution of universities to society. Etzkowitz and Chunyan (2008) observed that, while universities played a secondary role in early industrial society by providing trained personnel and basic research, universities now play an increasingly prominent role in the modern knowledge-based society, contributing the basis on which new industries and firms are built. Although this phenomenon has been pronounced in developed and newly industrializing economies, many developing countries are yet to realize significant change in the traditional view of universities as ivory towers of knowledge. Universities in such contexts largely remain institutions where knowledge is generated, transmitted, and preserved, with neither cognizance of its economic usefulness nor the aim of solving problems that would result in economic and social advancement. Developing countries that lag behind in the transformation of their knowledge institutions in response to the dynamics of intensely competitive industrial systems are characterized by relatively low capacity for the generation and use of economically relevant knowledge.

Theory and empirical studies show that technological innovation is the engine of growth, and the instrument of structural change in competitive economies (Solow 1957; Nelson and Winter 1982; Perez and Soete 1988; Romer 1990; Barro and Sala-i-Martin 1995; Kim 1997; Lall 2001). As

1 Adapted with permission from Kruss, G., Adeoti, J., Nabudere, D. (2012). Universities and knowledge-based development in sub-Saharan Africa: comparing university-firm interaction in Nigeria, Uganda and South Africa. Journal of Development Studies, 48(4), 516-530. Copyright 2012, Taylor and Francis, www.tandfonline.com. 
knowledge increasingly drives economic development, public universities are assumed to be critical sources for learning and innovation for firms in developed economies (Lundvall 1999; Mowery and Sampat 2005). There is now a substantial body of research and policy on university-industry links (UILs) and strategic alliances, and on the role of universities as key organizations of science and technology (S\&T) systems within the national system of innovation (NSI) framework.

Increasingly, in developing economies too, universities are expected to become more responsive and play a direct role in knowledge-based economic and social development. Governments and higher education institutions are debating and borrowing policy to promote interaction between university and industry, and a literature on UILs in developing economies is emerging (Eun et al. 2006; Hershberg et al. 2007; Mathews and Hu 2007; Wong et al. 2007; Liefner and Schiller 2008).

These trends are increasingly pervasive in sub-Saharan Africa, where knowledge intensification is recognized as critical to address development challenges. The available evidence suggests that, in most African countries, the nature and pace of transformation of universities and industry have been grossly deficient to meet the demands of contemporary development challenges. In sub-Saharan African countries, UILs are weak and the challenge of building local technological capability is daunting (Oyeyinka 1997; Okejiri 2000; Adeoti 2002). For sub-Saharan African countries to achieve the economic transformation that would result in significant poverty reduction, it is necessary to address the current weakness in university-firm interactions as an important instrument of building technological capability.

However, there is evidence to suggest that approaches and policies appropriate to advanced high-income economies are adopted in an imitative manner, without understanding the specificities of the very different contexts of low- and middle-income countries. There is a trend to import and promote models and practices that evolved over decades in a few top American and British research universities in relation to high-technology sectors. In sub-Saharan Africa, scientific, technological, and interactive capabilities of universities and firms differ vastly, and it is impossible to ignore issues of human development, poverty reduction, and equitable distribution of wealth. New models are required that extend existing conceptual frameworks and take into account global changes in knowledge generation, diffusion, and adaptation in relation to the specificities of African contexts.

There is thus growing debate about the application of the innovation systems approach in developing countries, with attempts to refine the national innovation system framework to inform policy (Cassiolato et al. 
2003; Farley et al. 2007; Lundvall et al. 2009). As yet, there is not a great deal of research on the role of universities in innovation and economic development that could inform contextually appropriate approaches and policy in sub-Saharan Africa. What does exist often engages with the challenges in aspirational and normative ways, proposing what should be and what could be (Myamila and Diyamett 2006; Etzkowitz and Dzisah 2007; Mwantimwa 2008). There has been little systematic research on the conditions of universities and firms and their potential for interaction across an NSI in the countries of sub-Saharan Africa (Muchie et al. 2003; World Bank 2009).

Therefore, in this chapter, we aim to examine the nature of universityindustry interaction in distinct African contexts. Such analysis can inform the "bracing" for the change that is required to build the partnerships between universities and firms that can deliver technological innovation. We conceive such partnerships to be characterized by an exchange of knowledge that results in tackling economic and social challenges, and consequently results in economic progress and poverty reduction.

The chapter is based on a regional study of university-firm interactions in sub-Saharan Africa. The focus is three countries selected at appreciably different levels of development: Uganda, Nigeria, and South Africa. The study examined the constraints on, and the features of, identifiable cases of UILs, with the broad objective of ascertaining how to address the constraints and promote a more productive regime of UILs appropriate to African contexts.

\section{CONCEPTUAL APPROACH AND METHODOLOGY OF RESEARCH}

The conceptual framework used to guide the empirical study drew largely from the literature on innovation studies. The innovation studies literature has not engaged systematically with the conditions and context of Africa's development (Lorentzen and Mohamed 2010). The literature reveals a number of possible ways to categorize the NSI in countries at different levels of catch up (Albuquerque 2001; Bernardes and Albuquerque 2003; Fagerberg and Srholec 2008; Ribeiro et al. 2009), but most schemes employ a methodology reliant on patent and publications data. It proved difficult to adopt such schemes to categorize African countries, where patenting and publications levels are too low to allow for meaningful distinctions between individual countries.

To allow for a more fine-grained distinction of the heterogeneity of innovation and economic development in the three countries at the macro level, we adopted the systems evolutionary framework proposed 
by Sercovich and Teubal (2008). The framework focuses on the interactions between firms innovation, knowledge systems, and policy learning in the catch-up process (UNIDO 2005). Building on the work of Imbs and Wacziarg (2003), Sercovich and Teubal posit that economies traverse three main "stylized" structural change-related phases as income per capita rises over time. Each phase has different mixes of diversity generation and specialization, leading to dynamic comparative advantages, manifest in new sectors and product classes that can successfully engage with global market conditions. The framework is suitable for our comparative purposes in that it does not propose invariant phases of development in a deterministic process, but represents a set of dynamic ideal type phases that vary across countries, sectors, and regions with distinct initial conditions. Transition between these phases is not automatic, but depends on the ways in which policy creates appropriate conditions to address system failures, strategic priorities, and latent opportunities of each phase. The framework was deemed particularly suitable because of its conceptualization of a "phase 0 " that encompasses countries with initial conditions that may not yet have reached critical thresholds.

This macro-level framework does not provide specific tools for analysis of UILs at the meso and micro levels. For this purpose, the research was informed by a complementary approach originally developed for a Carnegie Mellon survey of UILs (Cohen et al. 2002), and adapted for use in Brazil (Rapini et al. 2009). The approach examines the sources of innovation and research and development (R\&D) of firms, the knowledge intensity of different types of relationship, and the channels of interaction between universities and firms (see Introduction).

Evidence from two main data sources is presented in this chapter. First, there is a survey of firms in key regions and sectors in each country, which establishes their levels of innovation and R\&D activity, the channels and modes of interaction with universities, and perceptions of benefits and constraints by firms. The survey sample in Nigeria included 139 manufacturing firms in one of the three main industrial clustering axes, home to at least $60 \%$ of Nigerian firms in number and value addition (Adeoti 2009). In Uganda, the survey included 36 small and medium firms in the agro-processing and biopharmaceutical sectors in five industrial zones of Kampala, the capital and most developed region (Nabudere 2009). The core instrument was adapted to explore whether indigenous knowledge sources played a role in firm innovation and interaction. Firm data for South Africa differed in that they were based on a fresh analysis of national datasets from an innovation survey (2005) and an R\&D survey (2005-2006) that focused on the cooperation partners of firms.

Second, case studies were conducted of the interactions of selected uni- 
versity networks with firms in a biotechnology sub-sector in which there was comparative national specialization. Interviews were conducted with heads of department, senior managers, and senior researchers. In addition, the analysis drew on contextual studies of the economy and national policy, and of indicators of economic development, higher education, and innovation systems in each country.

\section{THE CHALLENGE OF KNOWLEDGE-BASED GROWTH AND INNOVATION IN THE THREE COUNTRIES}

\section{Overcoming Low-level Equilibrium and Establishing Threshold Framework Conditions: The Case of Uganda}

Uganda demonstrates the impact of years of political instability on a resource-based economy that has not yet succeeded in diversification (Nabudere 1980, 1990; Bigsten and Kayizzi-Mugerwa 1999). The majority of citizens still live in rural areas, and are reliant on the resilience of the informal subsistence agricultural sector. It remains an agriculturebased economy that includes both subsistence and export-oriented agroprocessing sectors. Over the past two decades, Uganda succeeded in breaking the trap of political instability, and is regarded as something of an African success story. This is attributed to sound macro-economic management and pro-market reforms, supported by proportionately very large inflows of official development aid, loans, and grants (ADB 2007; UNCTAD 2007; IMF 2008). There has been a limited diversification of traditional activities in production (UNCTAD 2007), but constraints and structural weaknesses remain (ADB 2007). These are high population growth, poor infrastructure, weak financial intermediation, and poor development of the agricultural sector. The innovation system is extremely weak and fragmented, and emerging S\&T capabilities may be too strongly tied to foreign R\&D interests (Nabudere 2009).

Historically, the establishment of universities in Uganda was a postcolonial process, an instrument to attain national independence, and to promote development and modernization in terms of nation building. The first national university was established as a college of the colonial university, and by the time it became a national public university, the path and model of a Western university had been firmly institutionalized. Uganda currently has expanded the number of public and private universities, but produces more social science than science graduates, and few postgraduates. Universities face financial constraints and have been forced to 
embark on reforms, drawing on models of the entrepreneurial university to privatize and commercialize programmes, but have had little impact on the country's industrial development (Mamdani 2007; Nabudere 2008a,b).

In terms of its trajectory of structural change, Uganda continues to display strong features typical of phase 0 , described in the systems evolutionary framework of Sercovich and Teubal (2008). That is, it is characterized by low-level equilibrium traps that are typical of many low-income countries and lead to economic and social stagnation at subsistence levels. A dynamic transition to conditions more typical of phase 1 is in process. The main feature is a wide variety of technical, organizational, and managerial experimentation and learning that develops innovative capabilities and competences of (predominantly small) firms in relation to products new to the firm or to the economy (rather than to the world) with selection largely at the firm level.

\section{Establishing Framework Conditions for Knowledge-based Growth: The Case of Nigeria}

In contrast, Nigeria clearly has made a transition from phase 0 , in that the oil-dominated economy displays a degree of diversification and the beginnings of selection at the firm level, typically in small firms through experimental activities alongside traditional activities. Nigeria displays features of stalling in phase 1. Transition is partly constrained by unresolved lowlevel equilibrium traps, and partly by path-dependent structural weaknesses. These weaknesses arise from the impact of the oil-based economy and related industrialization, which is based on consumer industries reliant on imports that have little local content or value addition (Adeoti 2009). Nigeria has experienced constraints arising from political instability, and a complex succession of civilian and military regimes (Kilby 1969; Ekundare 1973; Forrest 1993; Ihonvbere 1993). Agriculture contributes the largest portion of the non-oil producing sector (Kasekende et al. 2007). The share contributed by services is relatively high, which is explained by the large informal sector, and by value-added manufacturing, which as a percentage of gross domestic product (GDP) is lower than the average in sub-Saharan Africa (UNCTAD 2007). Without sufficient investment and policy prioritization, the NSI is still very immature, and is highly disjointed in establishment, management, and operation.

Similar to the case of Uganda, the university system in Nigeria was initiated in 1948 to create a pool of human resources for the civil service of the colonial government. Concurrent with the first signs of the development of modern industry in 1952 and particularly post-independence, it was recognized that few Nigerians had knowledge of the managerial and technical 
skills required for industrial production. The drive to improve the local supply of skilled labour saw the expansion of the number of universities in the 1960s and 1970s, which were claimed to be among the best in the British Commonwealth. However, as the economic crisis of the 1980s and 1990s weakened the capacity of the universities to generate knowledge, it became increasingly difficult for universities to reform and play significant roles as agents of economic development. Frequent unrest among students, industrial action on the part of academic staff, a decline in government support, the weaknesses of import substitution industrialization, and the incompatibility of African traditional knowledge with the knowledge generated in modern educational institutions, are all aspects that continue to shape the nature of university interaction with industry.

\section{Accelerating Innovation and Firm-level Selection: The Case of South Africa}

South Africa is typical of a country grappling with the challenges of traversing phase 2 . This phase is characterized by the emergence of higherlevel organizations in the form of new industries and markets, and the selection of products being primarily at the level of the firm, and largely governed by the market. The economy has become more diversified since the 1990s. Global exports indicate a comparative advantage in some sectors, but there is a predominance of "mineral-based items," so advancing the diversification of exports is still a key challenge (OECD 2007b, p. 27; Presidency, Republic of South Africa 2008). The expected foreign direct investment (FDI) inflows after 1994 have not materialized to any significant extent, which has widely been attributed to skills shortages and lack of infrastructural development. These structural deficiencies and systemic weaknesses relate to the economic and social divide, and the historical legacy of the unequal and segregated provision of education, health, justice, social services, and economic opportunities along racial lines. The highly unequal concentration of income leads to limited demand in home markets, and acts as a constraint on technological progress (Albuquerque 2007). The potential for parts of the emerging South African NSI to compete in the global knowledge economy is evident (NACI 2006; OECD 2007b). However, accelerated innovation and firm-level selection more widely across the economy are constrained by lack of skills and humandevelopment demands.

The South African higher education has long links back to the colonial period, and the first institutions were established in the late nineteenth century. Expansion of the system was driven by the early industrialization that accompanied the gold and diamond mining industries. The 
system was strongly shaped during the apartheid period, when racially defined and unequally resourced institutions developed distinct missions as primarily research or teaching institutions. With the advent of democracy in 1994, the university system has undergone extensive institutional restructuring to address this historical legacy, expand access, and enhance responsiveness to economic and social development goals. An expansion of the higher education system is required for a transition to phase 3, particularly in relation to producing a large pool of graduates in the science, technology, and engineering fields. However, there are concerns that it may not be possible to expand significantly (Kahn et al. 2007; OECD 2007b). The system faces challenges related to: the low participation rate; the concentration of enrolment in social sciences and humanities; and an unresolved low equilibrium trap in basic schooling that restricts the pool of students available for critical fields of science and mathematics and leads to quality problems (Moja and Hayward 2000; Favish 2003; Fiske and Ladd 2004). These conditions shaped the scale and nature of interaction with firms promoted by new S\&T policy incentives after 1994.

\section{Distinct Developmental and Policy Challenges}

Challenges in economic development, innovation, and higher education policy differ markedly between the three countries. In particular, they show marked differences from advanced economies that are more typically engaged in traversing phase 3 , where specialization and firm selection begins to prevail, and innovation becomes a strategic priority. Most middle-income developing countries remain stalled in phase 2, with only a few having successfully made the transition to phase 3 (e.g., Korea or Taiwan). The framework provides a good basis to compare African countries at the macro level. It highlights their distinct trajectories and the specific structural constraints on, and latent opportunities for, knowledgebased growth, innovation, and the emergence of UILs.

\section{FEATURES OF UILs}

In this section, we analyse trends at the meso level. We draw on the firm data to consider whether and how the scale and nature of the interactions with universities differ among the three countries. Analysis begins with the case of South Africa, which is closest to the typical pattern of UILs in advanced countries that are traversing phase 3 . We use this analysis to highlight the distinctly variant patterns of interaction in countries like Uganda and Nigeria, which are traversing into and through phase 1. 


\section{The Emergence of Networks: UILs for Innovation and R\&D in South Africa}

Typically, in phase 2, the challenge is to accelerate innovation. Firms increasingly attempt to enter competitive domestic and global markets by using innovation-related capabilities, and specialized selection emerges in some firms, including small and medium enterprises (SMEs), in some sectors. Interaction is typically with suppliers and users, but networks and cooperation become a strategic priority to take advantage of the capabilities of external knowledge partners such as universities, public research institutes, and technology centres. One weakness is that these are not well connected with, or co-evolved with, local knowledge and technology sub-systems.

Empirically, the patterns of interaction found in South African firms largely reflect this ideal type. Firms in general reported a relatively high rate of innovation in comparison with European Union averages (Blankley and Moses 2009). However, this type of innovative activity tends to be predominantly embodied in technology - through the acquisition of machinery, equipment, and software (54\% of innovative firms) and intramural R\&D (52\%). Only 19\% of firms engaged in extramural or outsourced R\&D. The source of knowledge and technology to inform innovation is more commonly other firms, particularly user and supplier or customer relationships, or publicly available knowledge sources. University R\&D is significant for only about 5\% of firms. Universities are more significant for firms performing R\&D, with a third reporting universities as their most common cooperation partner.

We see a set of technologically sophisticated firms interacting in networks with affiliated firms, suppliers, customers, and universities. The higher-level forms of organization that typically emerge in phase 2 are evident. A profile was constructed of the firms that innovate and perform R\&D, and are more likely to cooperate with universities. A firm's propensity to draw on local universities - whether for innovation or R\&D - is associated with larger firms, firms with higher levels of technological intensity, and firms more strongly linked to the high technology sectors. The propensity of small and medium firms to cooperate with universities is quite limited.

Strong sectoral differences are evident if we consider the proportion of firms in a sector that innovate, that innovate with interaction, and that innovate with university interaction (Table 1.1). Analysed a different way, the firms that cooperate with universities on innovation are more likely to be in the manufacturing sector ( $50 \%$ of the firms that cooperate with universities), followed by wholesale and retail $(20.5 \%)$, financial and business services 


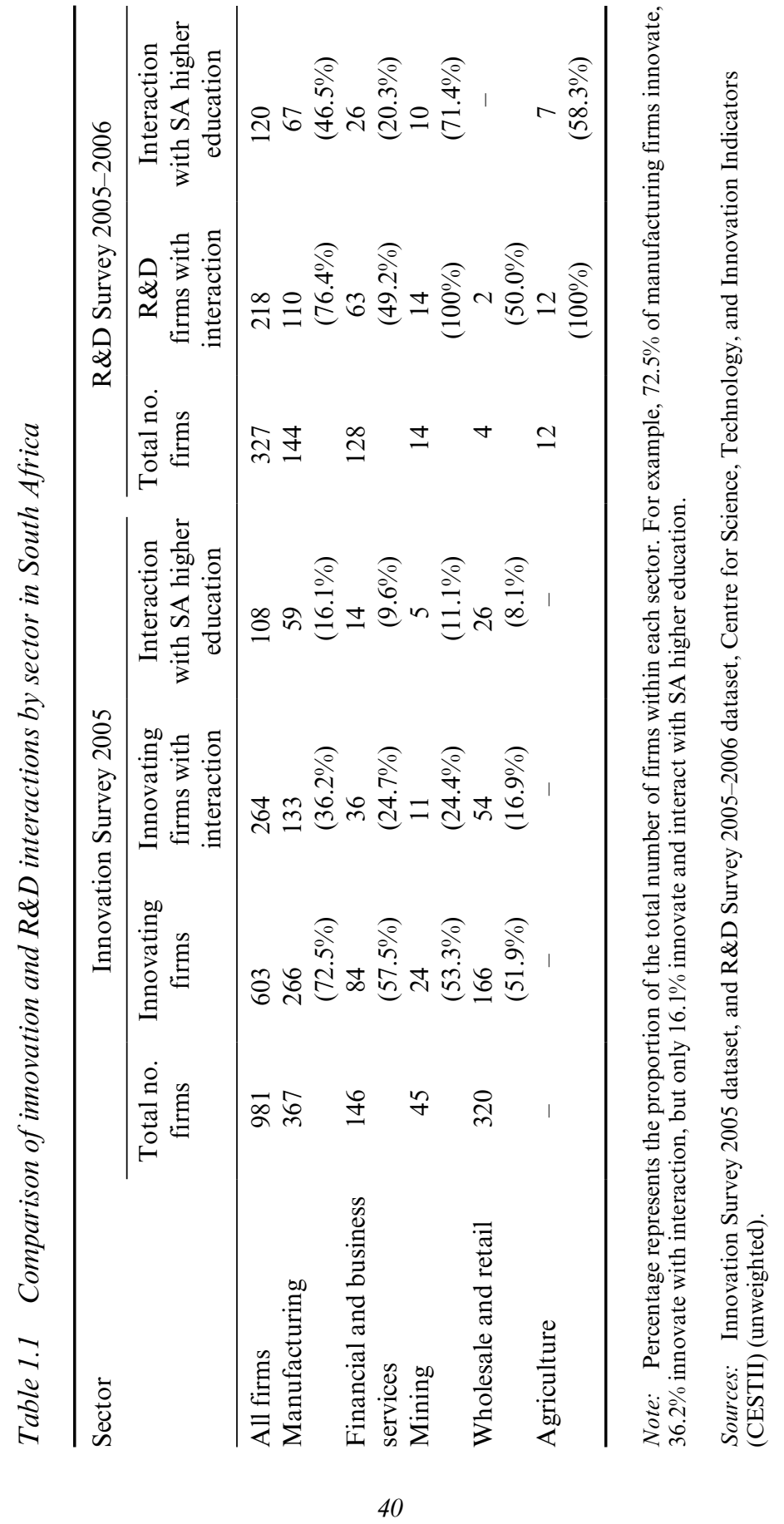


$(14 \%)$, and a few in the mining sector (4\%). Innovating mining firms tend to outsource $R \& D$, whereas financial and business services firms tend to conduct their R\&D in house. Similarly, cooperating R\&D firms are concentrated in the manufacturing sectors, with $92 \%$ of firms in high-technology sub-sectors reporting interaction with universities. Half of the firms performing R\&D in the financial and business services sector cooperate, but only $20 \%$ of these firms with universities. Although there are a small number of firms in the traditionally strong mining and agriculture sectors, all firms report cooperation on their R\&D activities - a high proportion with local universities, which reflects their strong historical roots (Kruss et al. 2009).

Higher R\&D and innovation intensity in firms is associated with higher levels of interaction with universities for the industrial sectors, particularly mining. This suggests that these firms engage with universities to complement existing capabilities and enhance competitiveness. The financial and business sector firms that cooperate with universities have lower levels of $R \& D$ and innovation intensity than those that do not, suggesting that these firms tend to cooperate with universities to substitute for missing R\&D capacity. Interaction thus tends to occur in a limited number of sectors where the fields of university research capabilities match the technological specialization and capabilities of the firms.

The form of interaction between universities and firms is typically formal, direct, and relatively knowledge intensive. It most commonly takes the form of a consultancy or contract to address immediate technology problems of firms, but technology cooperation networks are also found on a small scale (Kruss 2005).

Interaction with universities has benefits that enhance innovation and firm competitiveness. Firms that interact with universities reported considerably larger proportions of total turnover from innovative goods and services than do firms that cooperate with partners other than universities, and firms that do not cooperate at all. They also reported slightly higher levels of success in entering new markets or increasing their share in the market; higher levels of success in improving the quality of their goods or services; and increased capacity for production or services.

The data suggest that firms that innovate and perform R\&D and cooperate with universities represent the "unstructured islands of innovation activity" in the total landscape of firms that is typical of countries traversing phase 2 (Sercovich and Teubal 2008, p. 33). The South African firm data illustrate a pattern of emergent UILs in key sectors to support firm-level selection activities; however, innovation and R\&D networks are still not widely diffused across firms and sectors. This pattern contrasts with the Nigerian and Ugandan cases, where there is little match of firm demand and university capabilities. 


\section{Experimentation and Incremental Innovation: Low Firm Demand for Interaction with Universities in Nigeria}

Industrial firms in Nigeria are characterized by: a weak capability for the adoption, adaptation, and assimilation of largely imported technologies; low investment in R\&D activities; and relatively high investments in new plants and replacement of aged production equipment, mainly sourced through imports. Typical of phase 1, domestic products suffer reputation disadvantages, innovative networks are missing, and markets for innovation products and services are limited.

Our survey confirmed that the levels of innovation and R\&D in Nigerian manufacturing firms are low. The majority of firms are small or medium sized, and they most commonly conduct incremental innovation, using their own existing production processes to improve products or processes ( $74 \%$ of firms). Firms may innovate new to the firm $(24 \%)$ or to Nigeria $(16 \%)$, but very few report innovation new to the world $(9 \%)$ (Adeoti et al. 2010). The R\&D capability of firms is still weak, with very little investment assigned to formal in-house activity.

Almost $80 \%$ of firms reported that their own operations were the source for the suggestion and completion of incremental innovation projects (Figure 1.1). The most common external sources of knowledge were customers and competitors. Universities were in last place as sources of information and knowledge for new or existing innovation projects. They were less significant than publicly available external sources of knowledge, such as technical publications and reports, fairs or expositions, professional and trade associations, indigenous knowledge, and the internet.

When firms did cooperate with universities, the main channels of interaction were informal and publically available (e.g., publications and reports, and public conferences and meetings). These patterns were not unexpected in the early phases of selection and diversification, in which individual firms were involved in experimentation alongside traditional activities. Firms reported that they do not interact with universities because their own internal sources were considered sufficient, but equally, because of weak institutions and the lack of university capabilities. They generally perceived that universities had little to offer. Firms perceived the quality of research in the universities to be low, with the majority reporting that universities did not understand the firm's line of business and that the focus of universities was "big science" (Adeoti et al. 2010).

Unlike in South Africa, the relationship between universities and firms thus tends to be indirect. It is not formally structured, and it is not knowledge intensive. Incremental innovation relies primarily on the search and selection mechanisms of firms and their ability to assimilate publicly availa- 


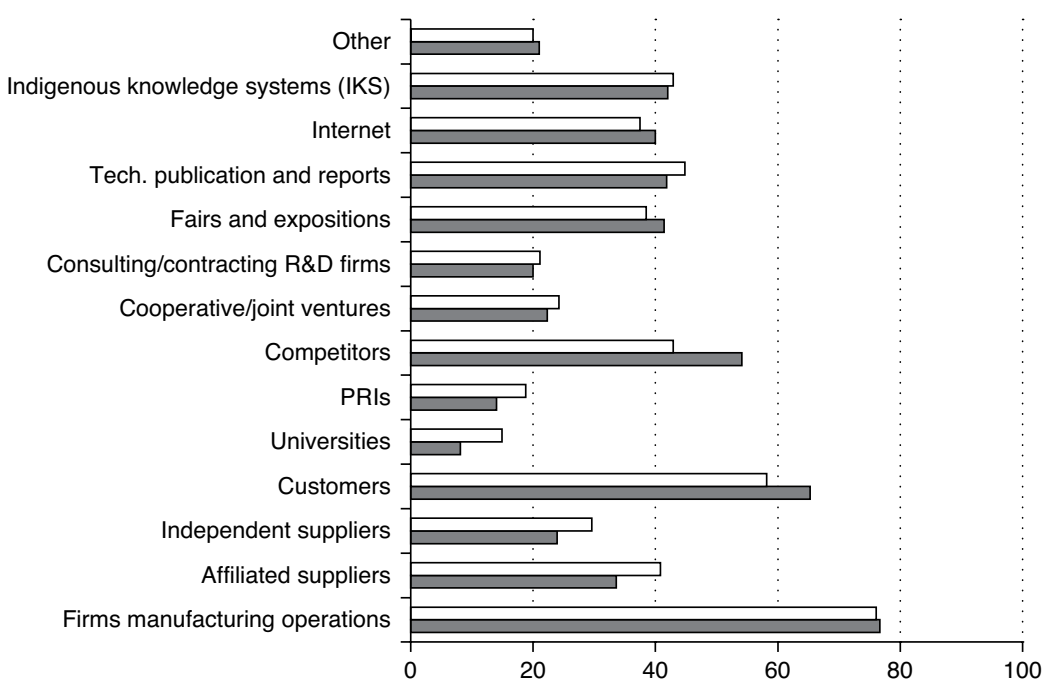

Note: $\quad$ White $=$ for suggesting new projects; black $=$ for completion of existing projects.

\section{Figure 1.1 Sources of information and knowledge (as percentage of respondents) for firms in Nigeria}

ble knowledge. Firm-level experimentation relies on internal resources and the insertion of the firm into value chains of affiliated suppliers, informed by customer demand. The innovation reported by the Nigerian firms relies on a "doing-using-interacting" mode of learning and knowledge acquisition (Jensen et al. 2007), which is characterized by internal processes of learning based on tacit knowledge and experience-based know-how acquired on the job. Also in contrast to South Africa, there is little evidence of a "science, technology, and innovation" mode of firm learning (Jensen et al. 2007). Therefore, there is little direct, formally structured or knowledge-intensive interaction with universities. The data highlight a major mismatch between the priorities and capabilities of manufacturing firms and the university sub-system, with little interaction or co-evolution of capabilities. A similar pattern is found in Uganda, with interesting variations.

\section{Experimentation and Regulation: Firms Seeking Missing Internal Capacity}

Uganda has relied on its peasant-based agricultural sector, and the economy has not diversified to a significant extent, in contrast with Nigeria. Foreign-operated multinational companies play a key role in 


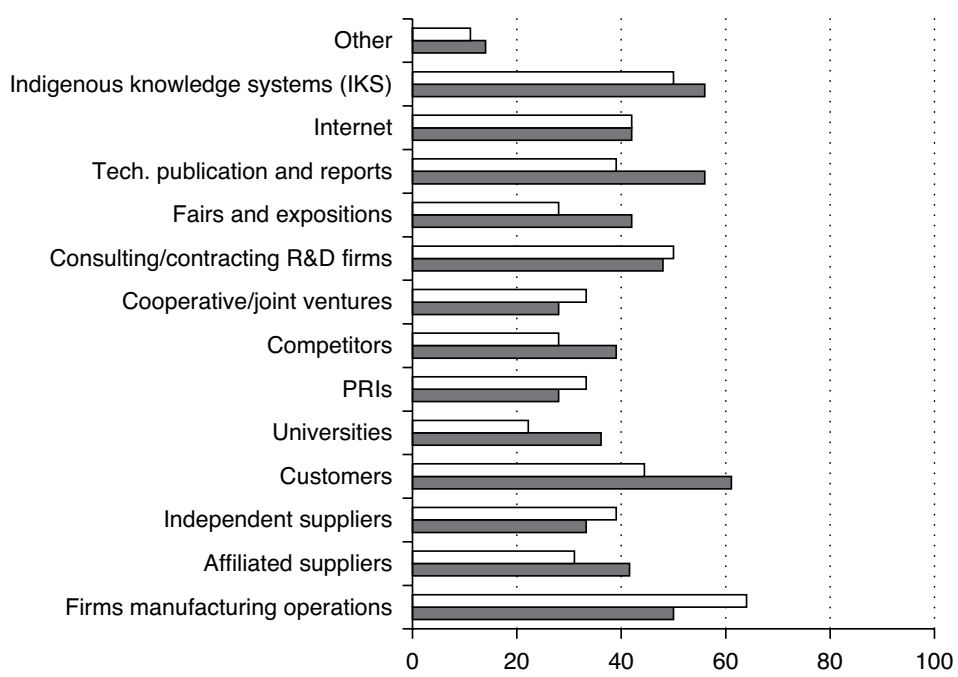

Note: $\quad$ White $=$ for suggesting new projects; black $=$ for completion of existing projects.

Figure 1.2 Sources of information and knowledge (as percentage of respondents) for firms in Uganda

industrial activity, and Ugandan-owned small enterprises find it difficult to survive the competition. The small sample of manufacturing firms is indicative of this trend. As in Nigeria, most of the innovative activities are incremental and are rooted in experiential learning within the firm. Product and process improvements are new to the firm or country. Firms invest very little in formal $R \& D$.

Customers, indigenous knowledge experts, technical reports and publications, and the firms' own manufacturing operations hold sway as the main sources of information for suggesting new projects for the majority of firms (Figure 1.2). The completion of existing projects relies heavily on the knowledge accumulated by firms in the course of their routine operations, followed by indigenous knowledge sources, and consulting and contracting R\&D firms. Less than a third ranked universities as generators of knowledge for their projects. As in Nigeria, this reflects the predominance of "doing-using-interacting" modes of knowledge acquisition, rather than firm learning that relies on S\&T. In the perception of the majority of firms, universities are not sought out because they are concerned with "big science," and they lack understanding of the firms" line of business. 
Where interaction with universities does occur, the most common channels of interaction are publicly available and informal. Only slightly different from Nigeria, these firms report a degree of direct but informal cooperation with university researchers: public conferences and meetings, informal information exchange, consultations with individual researchers, and publications and reports.

The very small group of enterprises that pursued interactions with universities to support their innovative activities were mostly intent on benefiting from new techniques and instruments, research findings, and laboratory facilities. Interviews revealed that these firms were seeking to compete in global markets. Quality control was an important motivation. The main objectives were: the performance of tests necessary to assure the quality of products and processes; assistance in quality control using university resources and public laboratories; and obtaining technological and consulting advice. These firms required external sources of knowledge to substitute for missing internal capacity. These requirements were primarily routine $S \& T$ and low-level capabilities of universities that could as easily be supplied by consulting R\&D firms. Thus, as in Nigeria, the data highlight a general mismatch between firms and universities. Of note is the promotion of direct interaction with universities to support experimentation in a very small innovative SME sub-sector.

\section{Two Distinct Patterns}

The empirical data suggest two broad patterns of firm interaction (Table 1.2). The first is associated with the developmental challenges of traversing phase 2. Firms in key sectors are increasingly developing their innovation and $\mathrm{R} \& \mathrm{D}$ capabilities and interacting with universities in more formal, direct, and knowledge-intensive ways, to complement existing or substitute missing internal capacity. However, this activity is not widely diffused within sectors or across the economy. The second pattern is associated with traversing phase 1 . There is a mismatch between firm demand and university capabilities so that interaction is largely informal, indirect, and not knowledge intensive.

There are variations to these patterns. The data from Ugandan show that the phases are not invariant, and that the transitions depend on the way policy creates conditions to address strategic opportunities, system failures, and latent opportunities of each phase. The following section considers how the development and co-evolution of policy capabilities shape the forms of UILs in a specific country. 
Table 1.2 Two patterns of firm interactions

\begin{tabular}{|c|c|c|}
\hline & $\begin{array}{l}\text { Mismatch and } \\
\text { indirect interaction }\end{array}$ & $\begin{array}{l}\text { Interaction in key sectors, } \\
\text { narrow diffusion }\end{array}$ \\
\hline $\begin{array}{l}\text { Main sources } \\
\text { of innovation }\end{array}$ & $\begin{array}{l}\text { "Doing, using, and } \\
\text { interacting" (DUI) modes } \\
\text { of innovation rooted in } \\
\text { experiential learning within } \\
\text { firm: own operations, } \\
\text { customers, and competitors }\end{array}$ & $\begin{array}{l}\text { "Science, technology, and } \\
\text { innovation" mode alongside } \\
\text { DUI modes, with main } \\
\text { sources users and suppliers } \\
\text { or customers, and publicly } \\
\text { available knowledge }\end{array}$ \\
\hline $\begin{array}{l}\text { Diffusion of } \\
\text { formal R\&D }\end{array}$ & Low levels of firm R\&D & $\begin{array}{l}\text { R\&D performing firms in some } \\
\text { sectors }\end{array}$ \\
\hline $\begin{array}{l}\text { Types of } \\
\text { relationship }\end{array}$ & $\begin{array}{l}\text { Publicly available } \\
\text { knowledge and technology }\end{array}$ & $\begin{array}{l}\text { Consultancy and contracts, } \\
\text { technology cooperation } \\
\text { networks }\end{array}$ \\
\hline $\begin{array}{l}\text { Channels of } \\
\text { interaction }\end{array}$ & $\begin{array}{l}\text { Informal, indirect, and not } \\
\text { knowledge intensive }\end{array}$ & $\begin{array}{l}\text { Formal, direct, and knowledge } \\
\text { intensive }\end{array}$ \\
\hline $\begin{array}{l}\text { Match of } \\
\text { demand and } \\
\text { capability }\end{array}$ & $\begin{array}{l}\text { Mismatch between } \\
\text { universities and firms }\end{array}$ & $\begin{array}{l}\text { Universities and innovating } \\
\text { and R\&D firms in key sectors } \\
\text { interact to complement or } \\
\text { substitute capacity, but not } \\
\text { widely diffused }\end{array}$ \\
\hline
\end{tabular}

\section{THE EVOLVING INTERACTION BETWEEN FIRM INNOVATION, KNOWLEDGE SYSTEMS, AND POLICY}

In traversing phases 0 and 1 , horizontal policy mechanisms that can support the development of S\&T institutions and threshold capabilities across the system are deemed more important than vertical policy mechanisms targeted at emergent competitive sub-sectors or at promoting UILs (Sercovich and Teubal 2008). The Ugandan pattern of interaction is shaped by the fact that, in a small country with a small number of universities, global funding and development agencies have directly encouraged the adoption of horizontal models of science, technology, and innovation policy. Donor agencies influence the policy of both governments and universities because they contribute significant proportions of national R\&D funding (UNESCO 2007). At the same time, targeted policy mechanisms have grown niche specializations that depend on the involvement of universities in firm networks, and promoted new forms of direct and more knowledge-intensive interaction. 
There is an emergent trend driven by government and foreign donor funding, and facilitated by intermediary organizations. The trend is to promote value addition in agriculture-related sub-sectors to grow export markets. For example, the government fostered a niche specialization in biopharmaceuticals based on indigenous knowledge of medicinal plants. A government export-promotion programme required that firms adhere to strict measures for chemical and quality control. To this end, it organized small firms that commercialize indigenous knowledge, and directly linked them with a university or public research institute. The firms interact with the universities to substitute for missing internal $R \& D$ capacity to be able to comply with international regulatory standards and promote global exports. This provides a positive example of co-evolution of university and firm capabilities stimulated by government policy intervention. However, across the Ugandan NSI, coherent and effective policy implementation mechanisms remain undeveloped, ad hoc, and fragmented. The questions are whether international policy is being adopted with sufficient understanding of domestic conditions and history, and whether it is possible for such targeted strategies to succeed in the absence of threshold conditions.

In Nigeria, in contrast, horizontal or targeted policy to support UILs has been largely absent until recently. Adeoti et al. (2010) argue that policy was deficient in identifying technological innovation as an engine of economic growth and development. Innovation has only recently been recognized in a new economic development strategy, and the introduction of a range of targeted sectoral interventions (Oyeyinka 2006). Historically, science, technology, and innovation were considered exogenous to Nigeria's economic development, and were acquired from outside by means of technology transfer. There have been few attempts to promote indigenous technologies and local sources on which new sectors could be based, in contrast with the Ugandan case. A "science push" approach, coupled with minimal public investment in S\&T, is a major constraint to building capabilities and to creating the conditions needed for UILs.

South Africa faces a similar challenge to Uganda. It has adopted international policy models, but, as is increasingly evident, insufficient attention has been given to appropriating these models in ways informed by domestic needs and unequal human development conditions. Unlike Uganda, there is a well-developed set of targeted funding and incentive mechanisms and new institutions (e.g., government and industry research co-funding programmes, innovation-incentive funding programmes, sectoral incubators, and technology platforms) to drive UILs aimed at addressing problems of technology achievement. The US paradigm was a strong influence, and is evident in policy mechanisms to promote technology transfer, commercialization, and incubation in the high-technology 
fields of biotechnology, nanotechnology, and information and communications technologies (ICTs). Recently, following OECD criticism of a lack of implementation of a commitment to "technology for poverty reduction," there has been renewed emphasis on a policy mission of "broadbased social innovation." Government and institutional policy learning is improving, but it is still a challenge to diffuse UILs across sectors and firms to support specialization. A major system failure is the lack of successful horizontal policy instruments to grow the education and training system. Therefore, critical skills shortages are a constraint on firms and universities, and on the development of the NSI.

Patterns of UILs are not solely shaped by the nature of firm demand. They are also shaped by national policies that promote S\&T and an NSI within the context of global trends and influences.

\section{RESEARCH AND INTERACTIVE CAPABILITIES FOR INNOVATION CAPACITY}

The Nigerian and Ugandan surveys highlighted the perception of firms that universities do not have the capacity to meet their needs. However, in all three countries studied, there are instances of knowledge-intensive networks that signal latent opportunities for interactions. It is important to investigate what is emerging, and what conditions and capabilities in universities facilitate these networks. In this section, evidence is presented from micro-level case studies. In Ugandan and Nigerian universities, we look at interactions in agro-food processing, a sector that has received policy priority given the high contribution of agriculture to GDP in both countries. Health biotechnology is examined in South African universities.

\section{University Support for Incremental Innovation and Productivity in Agriculture}

In Uganda, two newly established regional universities displayed virtually no evidence of interaction with firms, given a lack of research capacity. Interactive activity was concentrated at a large, long-established university based in the capital city, where emergent networks were evident. For the most part, these networked projects were oriented to break poverty traps, address problems of human development, and encourage knowledge intensification in traditional agricultural activities to enhance productivity. There were emergent creative attempts to use technology for local economic development. As well, there was evidence of collabo- 
ration with indigenous knowledge generators and users in the informal sectors, such as small-scale farmers based in cooperatives and community organizations. ${ }^{2}$ The role of the university in these networks matches the firm mode of incremental innovation, and is not strongly related to basic scientific research or knowledge generation. A key role is testing and quality assurance to support conformity to international standards. The university is typically involved in training, extension and advisory work, field trials, and monitoring of the adoption of new technologies. Such technology transfer and research diffusion activities have a long tradition, although they may now take new, more knowledge-intensive forms.

Many of the projects are beset by problems of sustainability, given their reliance on donor project-based funding and the dearth of core government funding. The establishment of university incubators, science parks, and technology transfer offices is evidence of the direct importation of interactive mechanisms from advanced economies that assume there is a viable industrial sector with innovation capabilities. It remains to be seen how successful these emergent efforts will be to commercialize and disseminate new technologies generated within a university. It will also be interesting to see whether the local conceptualization of science parks and incubators will be informed by the nature of the specific demand for incremental innovation and technology adaptation and diffusion by Ugandan firms and other productive agents such as communities, cooperatives, and farmers.

\section{Building the University Research System and Technology-transfer Mechanisms}

The first of three universities studied in Nigeria was an established large traditional university with a highly qualified academic staff aiming to transform into a postgraduate institution. The second was a young specialized federal land-grant university established as part of a move to promote modernization of agriculture. The third was a young technology university aimed at academic degree programmes in engineering and related fields to address the local industrialization. The universities rely strongly on (inadequate) government funding, and foreign donor funding is not sufficient to have a strong impact. The case studies illustrate the impact and effects of the structural deficiencies and system weaknesses typical of phase 1 within universities: acute shortages of resources; paucity

${ }^{2}$ For example, trials of an integrated pest-management technology that uses indigenous knowledge in a United States Agency for International Development (USAID)-funded consortium that includes American universities, Ugandan public research institutes, nongovernmental organizations, and a community cooperative that now includes 1300 members from 12 villages. 
of laboratory, science, technology, and engineering research and training capabilities; scarce cooperation and innovation networks; and the poor reputation of domestic products and services (Sercovich and Teubal 2008). These require horizontal policy interventions to enhance research capacity and research infrastructure.

In general, interaction with firms tends to operate in the interests of higher education, and is formalized primarily through industrial work experience and training schemes for students, or sponsorship agreements with large firms. Most firm-oriented interactions were informal, were effected through former students, personal ties, and professional associations, or involved consultancy services in relation to product analysis or processing of key crops such as cassava. These activities support the incremental innovation processes of the firms.

University research is generating adaptations of technology to suit local conditions, but these are often in advance of market demand. For example, research on postharvest technologies and food processing has led to a long list of applied research outputs that are not diffused to small firms and farmers: yam processing and utilization, fermentation technologies, varieties adapted to cultivation in the local climate, solar energy designs, or cost-effective and sustainable organic agriculture systems. There are no mechanisms to disseminate this technology to firms, farms, or small-scale producers, or to support university commercialization, so these achievements typically remain hidden or locked into the institution. One reason is the historical over-reliance on importation and foreign technology, which translates into veneration for imported goods and skills, and becomes a constraint on local knowledge generation and technology transfer. As in Uganda, the universities have recently put into place interface mechanisms such as research centres, business development units, and centralized laboratory services, which may enhance technology transfer. Similar to Uganda, the universities do display emerging evidence of creative structures that work with small firms, farmers, and local groups to transfer research that can enhance productivity in agriculture, that can potentially open new value-added niche sectors for export, and that build their research base. Such instances can be studied systematically, nurtured, and replicated to develop interactive capabilities alongside scientific capacities.

\section{Fostering Networks in Targeted Sectors in South Africa}

Biotechnology policy in South Africa represents a state-driven attempt to promote key firms and lay the basis for a new sector or industry. The challenges are vast because biotechnology is in its infancy, and is faced with 
limited research and technology capacity, a virtually non-existent industrial sector, and gaps in the value chain (Gastrow 2008). The first set of cases was located in a historically disadvantaged, relatively young, moderately research-capable university with strengths in niche areas, including biotechnology. Interaction primarily took the form of university-based spin-off micro-enterprises that offered bioinformatics consultancy services to foreign customers and clients. The second set of cases was based at a long-established, historically advantaged, well-resourced university with strong research capability and reputation. The cases all involved "frontier science" research, new to the world, but directly related to the human development health needs of South Africa and sub-Saharan Africa: HIV/ AIDS vaccines; tuberculosis; and heart disease and hypertension. Drug, vaccine, and device development is proceeding at various stages through trials to the market.

All of the firms involved are foreign, whether interacting in the role of sponsor, customer, supplier of services, or partner in a start-up company. Key gaps in the local biotechnology supply chain drive cooperation with foreign firms: local capacity for producing vaccines, even trial quantities, has been eroded; few internationally compliant and certified laboratory facilities for monitoring trials exist; the lack of local venture capital means that investment partners are sought abroad; and the small size of local demand drives the search for foreign partners to assist with access to global markets. These cases illustrate the challenges of developing conditions and capacity for science-led firm selection, and of creating an emergent new product class. The fragile links within the NSI need to mature over time. The fledgling local productive sector is not able to take advantage of the latent opportunity inherent in existing research and knowledge-generation capability. However, it is unlikely that universityled commercial ventures can drive the process without a core local productive sector with key capabilities along the value chain. It is significant that some South African universities do have levels of scientific production that are sufficiently strong to attract global firms as business or research partners.

\section{A DIFFERENTIATED POLICY APPROACH TO PROMOTE UILS}

The chapter examines the role of universities in knowledge-based development in low- and middle-income countries, particularly in sub-Saharan Africa. In a globalizing world, there is no case to argue that sub-Saharan African is exceptional, but systematic analysis of the conditions and 
capabilities of universities, firms, and interaction can provide insights informed by their "important peculiarities" (Altenburg 2008).

The framework of Sercovich and Teubal (2008) was under specified, and required conceptual refinement in relation to UILs as the unit of analysis. This was addressed by means of a complementary analysis of the nature of the channels of interaction. In considering the role of universities in economic transformation and poverty reduction in sub-Saharan Africa, the framework developed here highlights a significant degree of heterogeneity between countries that is commonly muted or missing in the research literature. Two broad patterns of interaction are distinguished, linked with the challenges of traversing distinct phases of structural change, but, in each country, shaped by evolving policy learning and university capabilities. The nature of UILs in South Africa is clearly more direct, formal, and knowledge intensive than in Uganda and Nigeria. Nevertheless, policy advances and university-level interventions in Uganda have stimulated the emergence, albeit on a small scale, of new more knowledge-intensive forms in specific sectors, which are not as evident in Nigeria. These potentially allow for universities to play a role in a more dynamic transition from phase 0 to phase 1 , whereas in Nigeria universities play less of a role, in a stalled transition through phase 1 .

Stronger analytical refinement and more systematic research in a wider range of countries covering more sectors are required to broaden and enrich the study of university interaction in sub-Saharan Africa. However, we believe that the attempt to link patterns of UILs at the meso and micro levels to analysis of the structural conditions, systemic weaknesses, and latent opportunities of dynamic phases of knowledge-based economic growth can yield insights to inform more appropriate policy interventions. As Sercovich and Teubal (2008, p. 12) propose:

The point is engaging less in viewing the domestic development issues in the light of the experience of successful catching up countries ... and more in assessing the latter's experience in the light of the specific circumstances of the countries that fail to catch up, with due attention paid to initial capability endowments.

In the following section, the insights from the empirical study are used to outline a differentiated set of strategic policy tasks as a starting point for "bracing" for change, and promoting university-firm partnerships in each country. 


\section{PROMOTING INTERACTION WITH SMALL- SCALE, INFORMAL, AND COMMUNITY-BASED PARTNERS}

The strategic policy development task for Uganda is how to promote mutually beneficial university interaction with small-scale firms, farmers, informal sector producers, and community-based cooperatives in a context in which threshold conditions are not yet in place. Rather than being imitative of practice in developed countries or strongly driven by foreign donor agendas, policy frameworks and university-level interventions need to be more strongly informed by emergent local practice and by the specific priorities of the phase of structural change and economic growth. University interaction should be primarily aimed at supporting incremental innovation, value addition, and productivity in the agriculture sector, which provides the livelihood for $80 \%$ of the population. Fledgling initiatives provide models to inform government funding and incentive mechanisms. Horizontal policy reforms of basic financial, political, and educational institutions are as significant, if not more, than micro-level interventions such as science parks that have a limited reach to a small number of firms. A key policy challenge for the university system is to extend science, technology, and interactive capabilities beyond the capital region, to the new universities in other areas.

\section{Building the S\&T System}

The strategic policy task for Nigeria at this point in time is different in emphasis from that of Uganda. The dual challenge is to build the S\&T system to enhance confidence in the capabilities of local academics, and to identify and nurture new forms of technology transfer that can promote research utilization and build interactive capabilities to open up the knowledge locked in to the universities. Mechanisms to turn around the high reliance on licences and royalties to the advantage of local learning and technological capabilities are required. The key role of universities relates to technology transfer, adaptation, and dissemination to support experimentation and incremental innovation on the part of local firms, small producers, farmers, or community enterprises, and to enhance productivity and value addition in the agricultural sector, which remains highly significant. Simply providing direct incentives to promote innovation is unlikely to tackle the system failure embodied in the existing mismatch between universities and firms, if the universities do not have the infrastructure, scientific, and interactive capability to respond to firm demand. 


\section{Toward Targeted Policy Intervention}

In South Africa, the need for horizontal policy to build the S\&T system and to strengthen and diffuse scientific capabilities remains a priority. However, targeted strategic policy intervention is equally important to strengthen nascent priority sectors, and there is evidence of such attempts. A range of interventions is required to deal with specific contextual challenges: greater security and seamless links in public funding cycles; incentives to attract specialized high-level skills; local private venture capital and investment agencies; and enhanced capacity of government departments and public funding and service delivery vehicles to implement programmes more effectively. The promotion of university-based commercial ventures is only possible in some universities and some sectors in an immature system of innovation. Institutional policy interventions should proceed with extreme caution, unless they are linked with priority sectors with potential comparative advantage. Policies to promote collaboration and networks that build on and diffuse existing small-scale innovation activity are important for universities to develop.

\section{Bracing for Knowledge-based Economic Transformation in Africa}

As Juma (2006) observed, a new economic vision for the African region, expressed at the highest level of government, should focus on the role of knowledge as a basis for economic transformation. Doing so will entail placing policy emphasis on emerging opportunities such as renewing infrastructure, building technological capabilities, stimulating business development, and increasing participation in the global economy. A caution was raised at the beginning of this chapter, against imitative and aspirational adoption of the promise of UILs in economic transformation. If Nigerian, Ugandan, or South African universities adopt models of firm interaction, technology transfer, incubators, or science parks uncritically and uninformed by systematic analysis of sectors and firms in their own contexts, they may not succeed in achieving their goals.

There is a vast literature documenting "best practice" for UILs in developed economies. Based on detailed analysis of country-specific conditions and of existing firm and university capabilities and patterns of interaction, it is possible to select the most appropriate kinds of interventions, mechanisms, and organizational structures to tackle the strategic policy task, and to address local priorities in a more sustainable way. 